\title{
An Activity-Based Undergraduate Software Engineering Course to Engage Students and Encourage Learning*
}

\author{
Eileen T. Kraemer \\ School of Computing \\ Clemson University \\ Clemson, SC USA \\ etkraem@clemson.edu
}

\author{
Murali Sitaraman \\ School of Computing \\ Clemson University \\ Clemson, SC USA \\ murali@clemson.edu
}

\author{
Joseph Hollingsworth \\ Computer Science Department \\ Indiana University Southeast \\ New Albany, IN \\ jholly@ius.edu
}

\begin{abstract}
The objective of this paper is to summarize our experience in teaching a software engineering course that emphasizes student learning through activities. It provides an outline and a template for educators interested in combining traditional topics with formal contract specification and verification topics, and engaging students in the classroom with a variety of activities that span the entire software lifecycle. Some of the activities are paper-based and are concerned with topics such as processes, requirements analysis and design, whereas others are tool-based and focus on specification and reasoning. Some activities involve pairs of students and others involve larger groups. The paper contains several illustrative examples. Student responses indicate that they find the activities engaging and conducive to learning. ${ }^{1}$
\end{abstract}

\section{CCS CONCEPTS}

- Software and its engineering $\sim$ Software creation and management

- Software and its engineering $\sim$ Formal methods

- Social and professional topics $\sim$ Computing education

\section{KEYWORDS}

Active learning, correctness, formal reasoning, student engagement, software lifecycle, tools, UML

ACM Reference Format: Eileen T. Kraemer, Murali Sitaraman, and Joseph E. Hollingsworth. 2018. An Activity-Based Undergraduate Software Engineering Course to Engage Students and Encourage Learning. In Proceedings of ACM European Conference on Software Engineering Education, Seeon, Germany, June 2018 (ECSEE '18), 9 pages. DOI: 10.1145/320987.3209100

Permission to make digital or hard copies of part or all of this work for personal or classroom use is granted without fee provided that copies are not made or distributed for profit or commercial advantage and that copies bear this notice and the full citation on the first page. Copyrights for components of this work owned by others than ACM must be honored. Abstracting with credit is permitted. To copy otherwise, or republish, to post on servers or to redistribute to lists, requires prior specific permission and/or a fee. Request permissions from Permissions@acm.org

ECSEE'18, June 2018, Seeon Monastery, Germany

\section{INTRODUCTION}

Software engineering does not need to be boring. A common perception among students is that software engineering courses often focus on topics that are perhaps necessary, but not particularly engaging. A common problem for educators is developing a software engineering course that presents important informal topics such as requirements analysis even while encouraging the use of more rigorous formal techniques. This paper explains the approach we have taken to address these challenges of integration and engagement through active learning, an evidence-based best educational practice in which students engage in the process of learning through activities and/or discussion as opposed to passively listening to an expert $[1,3]$.

Prior work has shown that teaching methods have substantial impact on student success: good practices can improve student engagement, interest in the subject matter, and learning while other practices can lead to low retention in the major [7,18,23,24,25]. Within computer science, active learning strategies such as collaboration, competition, peer instruction, roleplay, and flipped classrooms have been developed and applied at the collegiate level.

This paper describes several activities that we have developed over a number of iterations of teaching an undergraduate software engineering course. Some of these activities are pencil and paper based while others employ a freely available web-based Integrated Development Environment (Web IDE) [4,5]. Included are activities used during instruction on topics such as requirements analysis and software design, as well as activities used to highlight the benefits of design-by-contract and contract-based reasoning about code correctness in teaching the more formal aspects of software engineering.

C) 2018 Association for Computing Machinery. ACM ISBN 978-1-4503-6383-9/18/06 ..\$15.00 https://doi.org/10.1145/3209087.3209100 


\section{COURSE OVERVIEW}

The software engineering (SE) course at our institution has as a prerequisite a software development foundations course that introduces students to the basic concepts of software design, including the principles of modular design and design by contract. A summary of the earlier course, which serves as an exemplar course for integration of some of the key ideas in the ACM computing curricula, may be found in [11].

\section{Table 1: Weekly Course Outline}

\begin{tabular}{|c|c|}
\hline Week & Topics \\
\hline 1 & $\begin{array}{l}\text { Course introduction and grading policies; Introduction } \\
\text { to software life cycle. }\end{array}$ \\
\hline 2 & $\begin{array}{l}\text { Software life cycle; Process models; Project } \\
\text { management and metrics. } \\
\text { Activity: Requirements: Home Construction }\end{array}$ \\
\hline 3 & $\begin{array}{l}\text { Introduction to requirements engineering; } \\
\text { Requirements analysis continued; } \\
\text { Activity: Process vs. Product } \\
\text { Assigned: Team project } 1 \text { (Requirements) }\end{array}$ \\
\hline 4 & $\begin{array}{l}\text { Use case analysis; Introduction to software design; } \\
\text { Discussion of requirements project. } \\
\text { Activity: UML Use Case diagrams }\end{array}$ \\
\hline 5 & $\begin{array}{l}\text { Software design continued; Discussion of } \\
\text { requirements project. } \\
\text { Activities: UML Class diagrams, Sequence diagrams }\end{array}$ \\
\hline 6 & $\begin{array}{l}\text { Moving from design to specification; Formal and } \\
\text { informal specs; Component interface design issues; } \\
\text { Discussion of requirements project. } \\
\text { Activities: UML State and Activity diagrams }\end{array}$ \\
\hline 7 & $\begin{array}{l}\text { Exam review; Exam. Requirements team project due. } \\
\text { Assigned: Team project } 2 \text { (Design) }\end{array}$ \\
\hline 8 & $\begin{array}{l}\text { Introduction to analytical reasoning; Introduction to } \\
\text { mathematical modeling; Discussion of design project.. }\end{array}$ \\
\hline 9 & $\begin{array}{l}\text { Formal specification of components; Analytical } \\
\text { reasoning with objects. } \\
\text { Activity: Reasoning about Assignment }\end{array}$ \\
\hline 10 & $\begin{array}{l}\text { Specification-based testing and tracing; Extensions. } \\
\text { Design team project due. } \\
\text { Activity: Reasoning about objects (DBC) } \\
\text { Assigned: Team project 3: Implementing components } \\
\text { and QA }\end{array}$ \\
\hline 11 & $\begin{array}{l}\text { Loops and recursion; Component-based } \\
\text { implementations; Discussion of project } 3 \text {. } \\
\text { Activity: Reasoning with loops and recursion }\end{array}$ \\
\hline 12 & Exam review; Exam 2. Discussion of project 3. \\
\hline 13 & Implementation continued; White box testing. \\
\hline 14 & $\begin{array}{l}\text { Software maintenance; Student presentations. } \\
\text { Implementing components and testing project due. }\end{array}$ \\
\hline 15 & Tean \\
\hline
\end{tabular}

The SE course is taken by third and fourth year students. It is a onesemester course that contains coverage of all software lifecycle activities and places an emphasis on team-based software design and development. A third of the course grade is based on projects. The course also introduces formal specification and reasoning techniques with the aid of a web-based tool. A weekly course outline is given in Table 1 . The course is designed with the intent that students who successfully complete the course will be able to:

A. Describe the different practices that are key components of various process models (e.g., waterfall, iterative, and agile)

B. Describe how programming in the large differs from individual efforts with respect to understanding the context of changes, role of design and modularization, unit by unit quality assurance, and reuse

C. Using a particular software process, describe the aspects of a project that need to be planned, including requirements gathering, design \& specification, implementation, verification $\&$ validation

D. Interpret a given initial requirement to produce more complete requirements for a simple software system

E. Using a formal specification language, formulate the interface contracts of components and use them in code development, test plan generation, and reasoning about correctness

F. Function effectively as team members on a group project.

\section{ACTIVE LEARNING}

A variety of active learning techniques have been discussed in the literature as summarized in this section. We use variants of these techniques in our software engineering course.

In collaborative learning, students work together in order to achieve a common goal [2]. This method is typically characterized by students working in small groups on interdependent tasks. Accountability and responsibility are very important in order for the group to achieve its goal [29]. Slavin reports a number of positive outcomes for cooperative learning including increased student achievement, mutual concern among students and student self-esteem. Our course requires students to engage in various forms of collaborative or cooperative active learning through team projects and a number of in-class activities, as described below and in the following section.

Motivated by the benefits of active learning, pair programming is a key pedagogical technique in computer science education. In pair programming, two programmers, a driver and a navigator, work side by side at one computer in order to come up with a design, algorithm, code, or test. The driver types on the computer, while the navigator observes the work of the driver, looking for issues in the joint work. The two students switch roles frequently [33]. Pair programming has been found to decrease time to complete programs, improve a student's understanding of programming, increase student enjoyment, and improve student performance (i.e., higher completion rates and better exam performance) [21]. In our course, the third project, in which students specify, implement and verify modules for classes such as a stack or queue, requires students to engage in pair programming. 
Roleplay is an approach to collaborative learning that has been used to teaching software engineering amongst other topics. In this approach, students assume roles as supervisors and programmers in order to facilitate their understanding of the socio-technical aspects of the software engineering development process [12]. Students in our course engage in such roleplay in several activities, such as in learning principles of requirements analysis from different perspectives.

Group quizzes, a form of collaborative learning, have been shown to improve student behavior, attitudes and retention of course content [30]. In our course, students engage in pair quizzes on topics including the construction of UML use case, class, state machine, sequence and activity diagrams. Pair activities, when conceived carefully can avoid students from floundering and engage students in learning. Student feedback on this practice is included in our discussion of survey results in section 6 .

\section{ACTIVITIES FOR THE EARLIER LIFECYCLE PHASES}

We use an assortment of activities to motivate the concepts and engage the students. This section presents a few to illustrate the scope and style of these activities.

\subsection{Requirements Modeling Group Activity}

The requirements engineering discussion begins with various elements: elicitation, analysis, modeling, documentation, validation, and management. In each case, we use a variety of examples to present the key points.

\section{Table 2: Requirements Modeling Activity Table}

\begin{tabular}{|c|c|c|}
\hline Task & $\begin{array}{l}\text { Some Essential } \\
\text { Elements }\end{array}$ & $\begin{array}{l}\text { Some Irrelevant } \\
\text { Information }\end{array}$ \\
\hline $\begin{array}{l}\text { Electric } \\
\text { plumbing }\end{array}$ & $\begin{array}{l}\text { Detailed } \\
\text { Blueprints }\end{array}$ & Exterior elevations \\
\hline Carpet layers & Floor maps & $\begin{array}{l}\text { Detailed } \\
\text { blueprints, exterior } \\
\text { elevations }\end{array}$ \\
\hline Painting & $\begin{array}{l}\text { Floor maps, } \\
\text { interior elevations }\end{array}$ & Exterior details \\
\hline Bricks & Exterior elevations & Interior details \\
\hline Landscaping & $\begin{array}{l}\text { Lay of the land, } \\
\text { house location, } \\
\text { exterior elevations }\end{array}$ & Interior details \\
\hline $\begin{array}{l}\text { Heating } \\
\text { Cooling }\end{array}$ & $\begin{array}{l}\text { Floor maps, } \\
\text { interior elevations }\end{array}$ & Exterior details \\
\hline
\end{tabular}

The modeling that is necessary for different participants of a home construction effort provides an illustrative example. In one discussion in one class that spans a few minutes, groups of students take the roles of different stakeholders, such as plumbers, electricians, carpet layers, bricklayers, etc. They develop questions designed to elicit the requirements relevant to those perform that task and discuss the type of model that would capture those requirements. At the end of the discussion, they produce a table such as the one shown below on the whiteboard. For each stakeholder, the table shows what elements of a home are essential to model and what elements are irrelevant from the different perspectives.

\subsection{Process vs. Product Group Debate}

The SE course is typically the first time students are introduced to a software process. Early in the course, students often students fail to appreciate the importance of process. After an introduction to process models and process quality, we divide the class into two large groups with one group taking the position that process quality is more important and the other taking the position that product quality is more important. Within these large groups, students discuss the ideas in multiple smaller groups. At the end of the discussion, the groups take turns to present their compelling case in one statement on the white board. Here are some examples of their statements.

- $\quad$ Products are the bottom line.

- If there is no quality process in place, quality products won't result.

- A good quality process is necessary to sustain a business.

- Customer satisfaction ultimately depends on good products.

Of course, at the end of the discussion, we conclude that they are both important. In their responses, the discussion is often noted by students as both entertaining and informative.

\subsection{UML Diagram Activities}

UML diagrams are taught using a multi-stage, scaffolded process for increasing engagement and accountability. The process begins with a short lecture presentation on the purpose of the diagram type (e.g., use case, class, sequence, state, or activity) and then employs the interactive construction of a diagram based on student input. Next, students are asked to engage with the material by working in pairs to construct a diagram, based on instructions such as those given in this subsection. Instructions for a sequence diagram activity are summarized below.

Draw a UML 2.0 sequence diagram to capture the behavior of a simple payroll system that behaves in this way: A Payroll class for an information system associated with a chain of hardware stores has a calcTotalPayroll() operation that calculates the total payroll expense for a given month. It queries a Store class to determine the payroll expense for a particular store using a getStorePayroll() operation, which in turn calls the getPayroll() operation on Employee class objects. Your diagram should include suitable use of the "foreach" construct. 
Instructions for a state-machine diagram activity are given next.

Draw a UML 2.0 state machine diagram to capture the state of happiness. You need to find love and money for happiness. After you find the above, you need to find one more thing for happiness. This may be religion for some. For some others, this may be a football team. Also note that you may lose anything you find!

Students work in pairs for an appropriate amount of time (10-15 minutes) and then one or more student volunteers comes to the board to present their results and to get feedback from the class. At the next class, a quiz is administered, introducing a higher level of accountability. Some quizzes are taken solo, while students may elect to work in pairs for other quizzes. The solo/paired nature of the quizzes is unannounced to maximize student preparation. In the survey results of Section 6, students comment on the benefits of this approach.

\section{DESIGN-BY-CONTRACT SPECIFICATION AND REASONING ACTIVITIES}

The web IDE is a tool we have developed that supports teaching contract-based reasoning topics using various software components. The software components in the IDE's library have specifications based on RESOLVE, which is a programming language that includes an integrated specification language, and a mathematically sound verification system [26, 27]. The language, independently and in concert with other popular languages (e.g., [28]), has been used in introductory computer science courses and software engineering courses for nearly 30 years. Over 25,000 students spanning several institutions in the US have used the language and its framework for understanding formal contract specifications and mathematical reasoning [13]. Prior results show that it is possible to teach these principles effectively [6]. Several tools have been devised and used $[4,5]$.

The screenshot in Figure 1 shows an opening screen of the web IDE with its Component Finder listing the introductory activities that are available in the IDE.

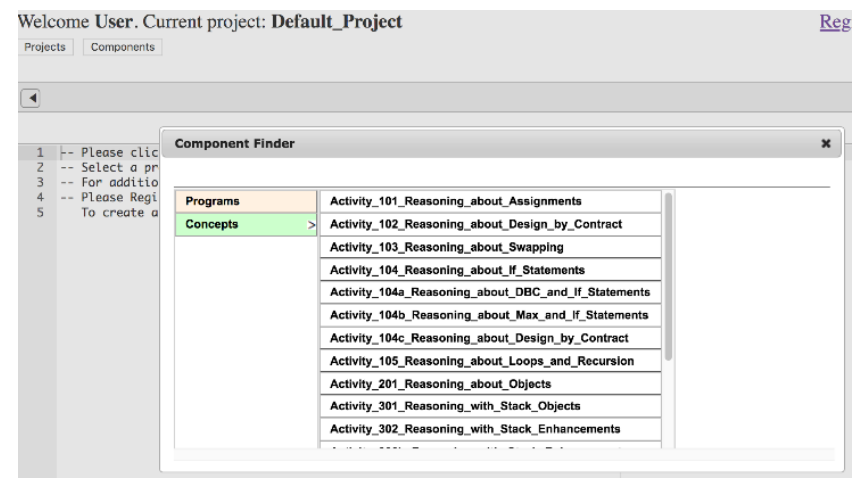

Figure 1: Web IDE \& Component Finder

\subsection{Introductory symbolic reasoning}

In Activity 101: Reasoning about assignment, seen in Figure 2, we ask the student to reason about the behavior of a traditional three assignment swap of the values stored in two integer variables. The "Remember" statement on line 10 causes the current values of variables I and $\mathrm{J}$ to be stored as \#I and \#J. The swap is performed on lines $12-14$. The activity comes preloaded with the assertions about the current and previous values of variables I and $\mathrm{J}$ (lines 16 and 17). The activity instructs the student to enter in an assertion about the value of $\mathrm{K}$ on line 18 .

A key goal of the activity is to teach symbolic reasoning-general reasoning about a piece of code without making particular concrete assumptions about input values. Such symbolic reasoning is key to the ability to develop specifications of program behavior.

In the code, ":=" denotes assignment. Students in a junior-level software engineering course recognize the utility of reserving equals ("=") for mathematical equality in assertions to avoid confusion. The assertion at line 16 states that the value of I is equal to the value of $\# \mathbf{J}$ (its value at line 10). Likewise, for the assertion " $\mathrm{J}=\mathrm{\# I}$ " on line 17, J's value at line 17 is equal to I's value at line 10. When the MP-Prove button is clicked, the underlying verification system attempts to prove the three assertions.

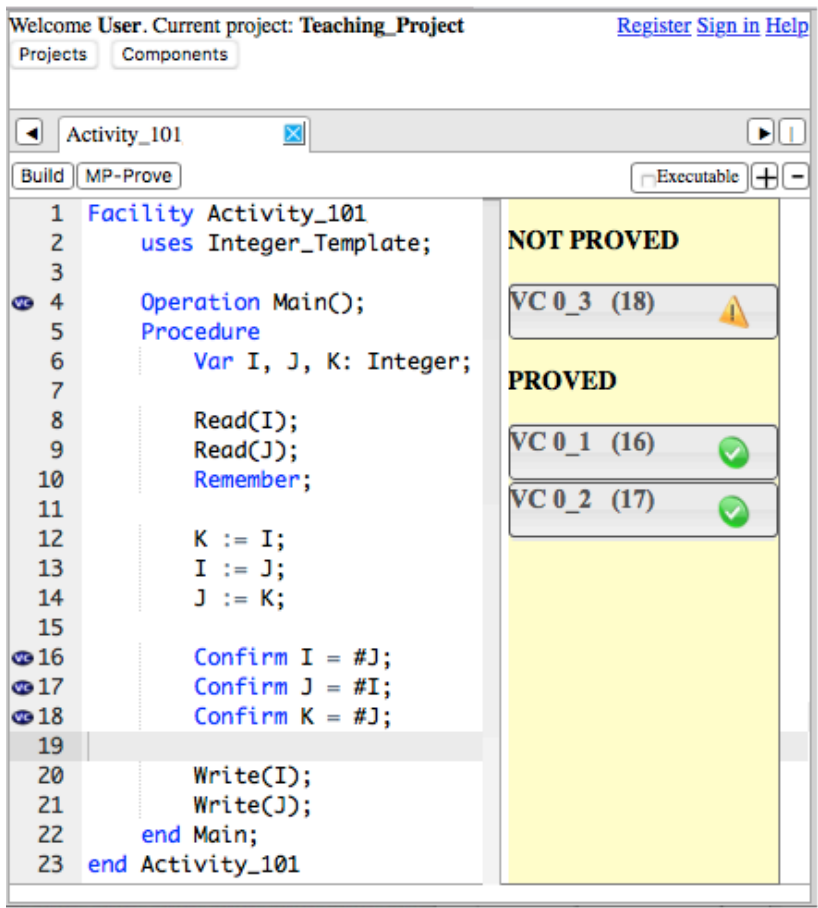

Figure 2: An Elementary Reasoning Activity

In this example, at line 18 the student inserted $\mathrm{K}=\# \mathrm{~J}$, which is not true. Clicking on MP-Prove caused the verifier to provide the feedback seen to the right, indicating that feedback to the student 
that the assertion on line 18 could be proved correct, while the assertions on lines 16 and 17 were proved correct. At this point, if the student modified the erroneous assertion to $\mathrm{K}=\# \mathrm{I}$, and then clicked MP-Prove again, all three assertions would then verify.

By utilizing abstract inputs of variables in the assertions on lines 16,17 , and 18 , the student is reasoning symbolically about the values of the variables I, J, and $\mathrm{K}$, and not about specific values, such as would be true with traditional testing on specific inputs.

Figure 3 shows Activity 102 - a sequence of design-by-contract [16] activities. While it is difficult to see the details, it is included only to illustrate that each activity has specific items for students to do, beginning with an introduction, followed by activities that facilitate guided and inquiry-based learning.

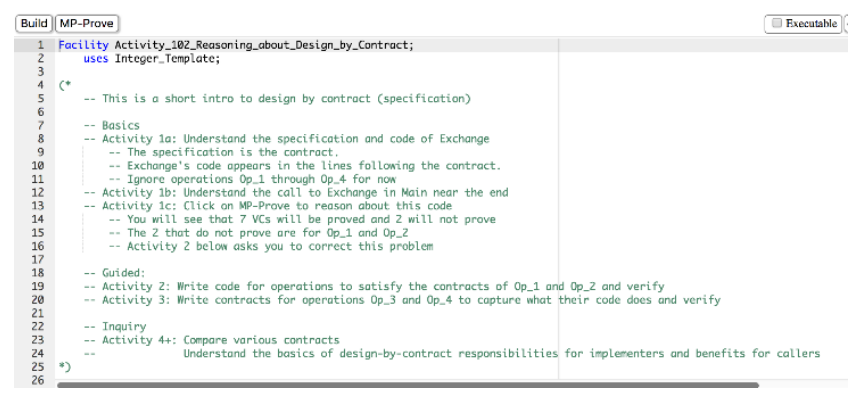

Figure 3: Sub-activities to teach Design-By-Contract

\subsection{Reasoning about Objects}

Figure 4 shows Activity 201_Reasoning about Objects, which asks the student to reason about a simple two-dimensional grid world. In this example, we have created an instance (named GPF) of the Grid_Positioning_Template so that variables declared from GPF are constrained in the $\mathrm{X}$ and $\mathrm{Y}$ directions from 0 to 3 .

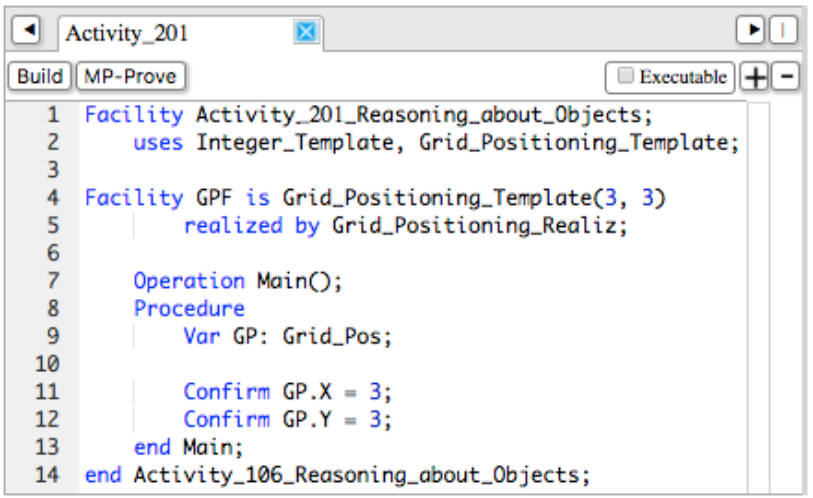

Figure 4: Grid Position Activity

The constructor has initialized variable GP to be at location $(0,0)$, so the assertions on lines 11 and 12 will not verify when MP-Prove is clicked. The activity asks the student to implement Operation Main so that it will verify correctly. Figure 5 shows the Grid Positioning contract with a number of its operations elided. It mathematically models a grid position as an ordered pair and provides operations to check and manipulate that position. Details may be found elsewhere [14, 27].

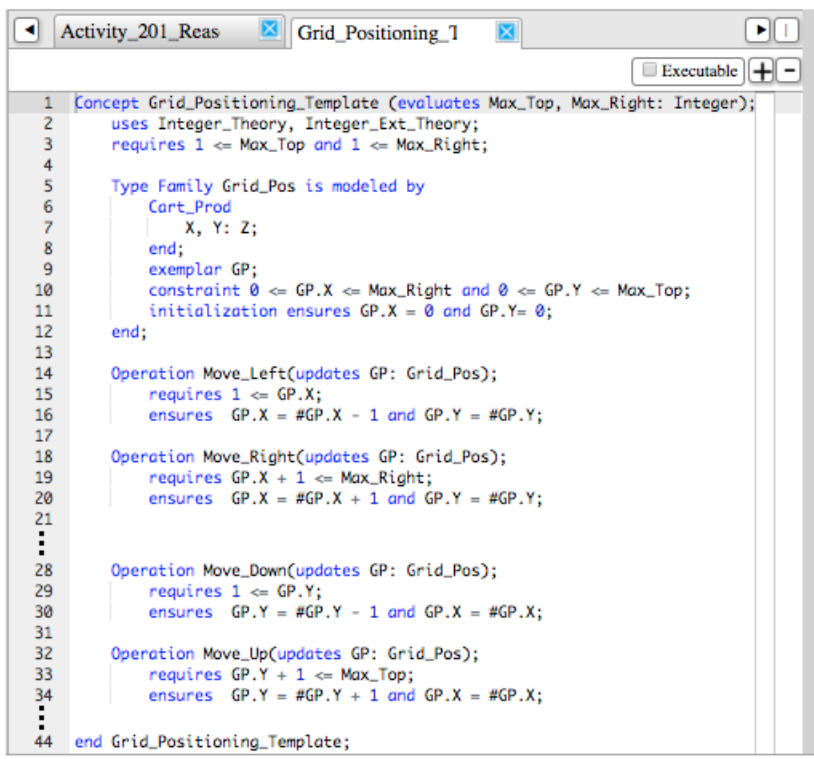

Figure 5: Partial Grid Positioning Contract Specification

The student must examine the contract specifications to understand the initial Grid position and use some combination of "Move" operations to implement Main correctly. Figure 6 shows Main correctly implemented and verified.

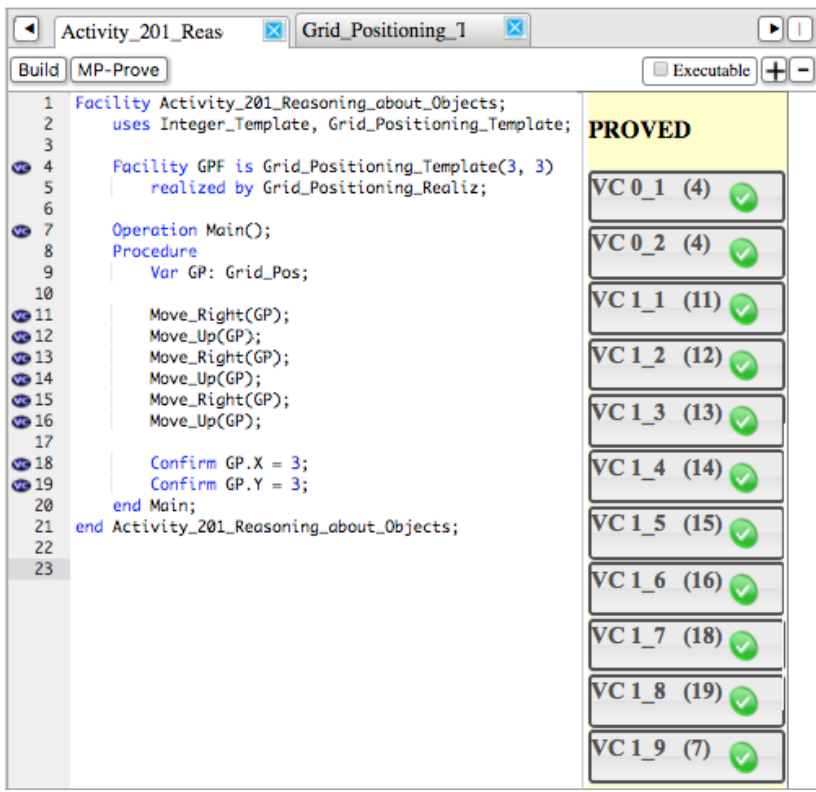

Figure 6: Student Activity and Response

The second part of Activity 201 asks the student to specify (i.e., write a contract) and implement a new operation called Move_NE. Figure 7 shows an example solution - an operation specification, its code, and its call from Main. By engaging in this activity, 
students gain hands-on experience with separation of specification and implementation.

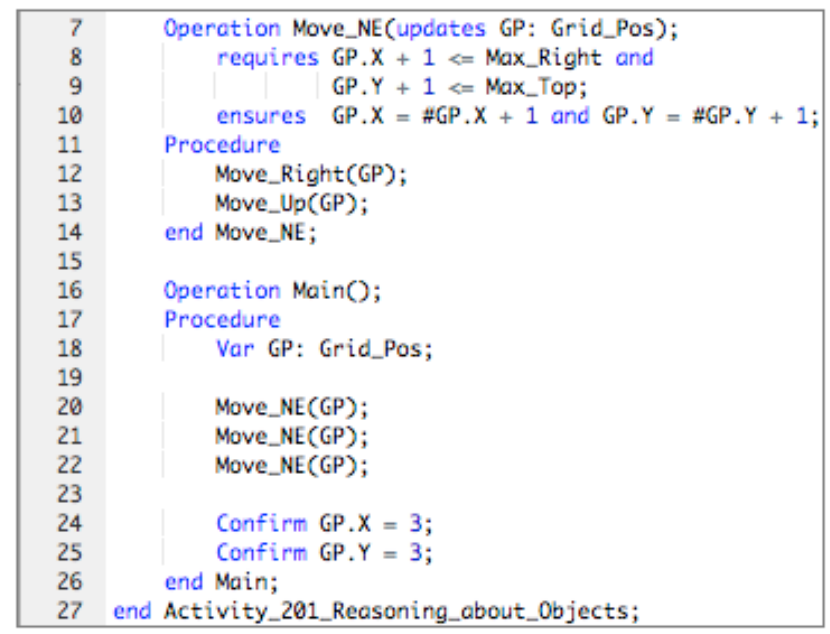

Figure 7: Student Activity in Writing Specification and Code

\subsection{Reasoning with loops and invariants}

Later activities engage students in writing invariants that capture key facts that explain why code works. For example, Figure 8 shows a loop invariant activity. Here Append is an operation that merges the contents of one queue with another. This activity asks the students to replace the "true" found on line 17 with a loop invariant that supports proving operation Append. An automated analysis of student responses to the activities and common problems in determining invariants arediscussed in [22]. Pinpointing difficulties students have in developing proper invariants is one of the goals.

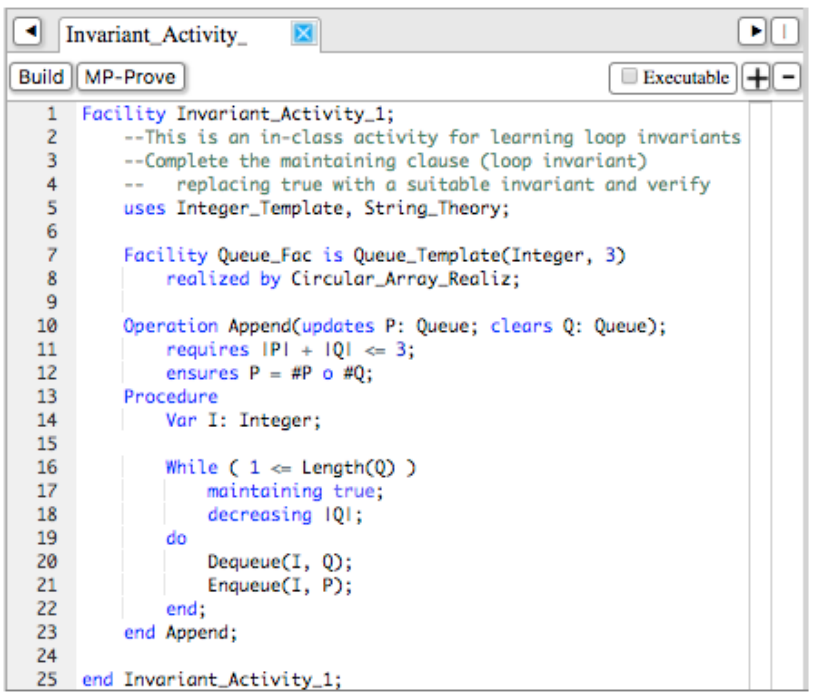

Figure 8: A Loop invariant Activity

In project assignment \#3, students will construct their own verified components and use them in their programs. Some components students develop are discussed in [4].
While we have used the RESOLVE approach for teaching reasoning in our course because it has ready-made activities and freely available web-based tools without need for installation, it is possible to use other systems, such as those summarized in [15]. We also note that there have been several other efforts in teaching formal methods in software engineering courses using contracts and specification languages, such as $[8,10,20]$.

\section{STUDENT RESPONSE AND ANALYSIS}

We conducted a survey of the students in two sections of the introductory software engineering course during the spring semester of 2018. Although the sections have different instructors, the same materials are used and the sections stay largely in sync. Occasionally the instructor of one section provides a guest lecture for the other section, or a graduate student may conduct a lecture.

The survey contained seven Likert scale questions, as follows: 1Strongly disagree; 2-Disagree; 3-Neutral; 4-Agree; 5-Strongly Agree, and two free response questions. The survey was conducted via the course learning management system, approximately midway through the course. Responses are included from those students who provided consent for their course materials to be included anonymously in research, representing 44 of 50 students in section 1 and 22 of 36 students in section 2. Questions and results are reported in Table 3 below. Responses from the two sections have been combined in this presentation. In column 2, we report the percent of students who assigned either a Strongly Agree (SA) or Agree (A) rating, indicating a favorable response. In column 3 we include as well the students who assigned a Neutral (N) rating, indicating a favorable-to-neutral response.

\section{Table 3: Student Response to Activities}

\begin{tabular}{|l|l|l|}
\hline Survey question & $\begin{array}{l}\text { SA } \\
\text { A }\end{array}$ & $\begin{array}{l}\text { SA }+\mathbf{A}+ \\
\text { N }\end{array}$ \\
\hline $\begin{array}{l}\text { 1. The paper-based paired activities in the } \\
\text { class are engaging. }\end{array}$ & $69 \%$ & $92 \%$ \\
\hline $\begin{array}{l}\text { 2. The paper-based paired activities in the } \\
\text { class help my learning. }\end{array}$ & $72 \%$ & $91 \%$ \\
\hline $\begin{array}{l}\text { 3. The computer-based paired reasoning } \\
\text { activities (e.g. last lecture) in the class are } \\
\text { engaging. }\end{array}$ & $52 \%$ & $89 \%$ \\
\hline $\begin{array}{l}\text { 4. The computer-based paired reasoning } \\
\text { activities (e.g. last lecture) in the class help } \\
\text { my learning. }\end{array}$ & $54 \%$ & $86 \%$ \\
\hline $\begin{array}{l}\text { 5. The product vs. process group discussion } \\
\text { in the class was beneficial. }\end{array}$ & $63 \%$ & $88 \%$ \\
\hline $\begin{array}{l}\text { 6. The home construction requirements } \\
\text { modeling group discussion (where } \\
\text { subgroups took the roles of plumbers, } \\
\text { electricians, brick layers, etc.) in the class } \\
\text { was beneficial. }\end{array}$ & $68 \%$ & $85 \%$ \\
\hline
\end{tabular}




\begin{tabular}{|c|c|c|}
\hline $\begin{array}{l}\text { 7. The paired UML diagram (e.g., state } \\
\text { diagram) activity in the class was } \\
\text { beneficial. }\end{array}$ & $78 \%$ & $92 \%$ \\
\hline
\end{tabular}

Overall, students found the activities to be both engaging and useful for learning. While the computer-based reasoning activities are less favorable in the combined data, there was no measurable difference between paper-based and computer-based activities in section 1 (with the larger sample size of 44 students). The significant difference was essentially between sections in their responses to the computer-based paired reasoning activities, with $63 \%$ of the larger section 1 sample providing a favorable response versus only $36 \%$ of the section 2 (with 21 consenting students). Since there was not much difference among different activities in section 1, the difference in section 2 is likely due to the coincidence of the computer-aided activity class being taught by a student with limited experience, employing computer-aided instruction for the first time. Other lectures of both sections were taught by experienced professors. This indicates the importance of appropriate motivation and context for these activities.

The free response questions were as follows:

1. Give an example activity you liked or disliked. You may feel free to write more than one.

2. Give an example of what you learned from your partner or what you helped your partner learn in one of the activities. You may feel free to write more than one.

For question 1, student comments were heavily weighted towards identifying activities that they liked, with 15 students identifying benefits of the home construction activity and 15 identifying the paired UML diagram construction activities as particular favorites. Also identified by students were the reasoning activities (7 students) and the role-playing activity (4) and process/product activity (3). Student comments provided insight into their perceptions of benefits.

One student wrote: "The construction activity was nice \& helped me understand some of the concepts behind software engineering. It also helped solidify the importance of communication when it came to software development." Another commented on paired work with UML diagrams: "Doing diagrams in pairs is always engaging in some way because each person always brings a different perspective on how something should be laid out, and both people help fill the gaps in each others' understanding of the diagram/the system we're trying to lay out." Yet another wrote: "An Activity I liked was where we created the state diagrams to get to the final state of happiness. I think the freedom and creativity that the activity gave us helped us learn the concept quicker and retain the information better." Several students noted that they would like to have additional opportunities for feedback on the diagrams they create.
We again saw a difference between section 1 and section 2 on the reasoning activities, with no students in section 1 stating that they disliked them while three students in section 2 did so. A student who liked the reasoning activities wrote: "I thought that the activities using the reasoning examples on the computer were pretty beneficial to my learning. Being able to test what is wrong and what is right at a sudden notice helped me learn exactly where my reasoning was right or wrong." A student who disliked the reasoning activities wrote: "I strongly disliked the Begin to Reason activities. .. I absolutely do not understand what the reason behind Resolve is ... it's not something that I'll ever use in my real life". It will be interesting to compare the sections again as the semester progresses and the section 2 students have more experience with the reasoning activities under the supervision of an experienced professor.

Finally, several students identified the team project as a favorite activity. One student wrote, "I think the project is very interesting because you let us go all out. We really get to stretch our minds to figure out a good model for such a system, looking for problems etc. I really enjoy it."

For question 2, students focused on the paired work with UML diagrams and how working together motivated them to work through the meaning of the diagrams and to sort out the details of the notations. Another focus of student responses to this question was communication and teamwork. One student wrote, "A lot of times on quizzes, I learn from my partner. Often times, when we're drawing diagrams there will be a little detail that I forget about or didn't fully understand in the lecture. I have helped my partners as well. Working with partners on quizzes has also helped to meet students in the class that we can text when we are confused about a concept or assignment." Another student wrote, "Working with a partner in a testing environment helped me better work with partners or teams in general. Communication in a limited time setting was important for quizzes and that type of communication translates to how I have learned to communicate and work in a larger peer to peer or team environment." Yet another student commented, "I learned that I do better when I'm working with others. There's plenty of stuff that I learned material wise, but the greatest lesson is that two minds are better than one."

\section{CONCLUSIONS}

This paper has presented an approach to teaching a software engineering course that employs active learning for in-class instruction. Illustrative example activities along various stages of the software lifecycle are discussed. The activities involve group collaboration and peer learning, and they are both paper-based and tool-based. Responses from students to the approach are positive. They agree that the activities make the classes engaging and find them to be conducive to learning.

\section{ACKNOWLEDGMENTS}

We thank the members of the software engineering and computer science education research groups at our and other participating 
institutions for their inputs to the contents of this paper. We also acknowledge that this research is funded in part by U. S. National Science Foundation (NSF) grants DUE-1611714 and DUE1646691. Any opinions, findings, conclusions, or recommendations expressed here are those of the authors and do not necessarily reflect the views of the NSF.

\section{REFERENCES}

1. Charles C. Bonwell, and James A. Eison. 1991. Active Learning: Creating Excitement in the Classroom. 1991 ASHE-ERIC Higher Education Reports. ERIC Clearinghouse on Higher Education, The George Washington University, One Dupont Circle, Suite 630, Washington, DC 20036-1183.

2. Kenneth A. Bruffee. 1993. Collaborative learning: Higher education, interdependence, and the authority of knowledge. Johns Hopkins University Press, 2715 N. Charles Street, Baltimore, MD 21218-4319.

3. Arthur W. Chickering and Zelda F. Gamson. 1987. Seven principles for good practice in undergraduate education. AAHE bulletin, 3,7 .

4. Charles T. Cook, Heather Harton, Hampton Smith, and Murali Sitaraman. 2012. Specification Engineering and Modular Verification Using a WebIntegrated Verifying Compiler. Proc. 34th International Conference on Software Engineering, IEEE/ACM, 1379-1382.

5. Charles T. Cook, Svetlana Drachova, Yu-Shan Sun, Murali Sitaraman, Jeff Carver, and Joseph E. Hollingsworth. 2013. Specification and Reasoning in SE Projects Using a Web-IDE. Proc. 26th Conference on Software Engineering Education and Training, IEEE.

6. Svetlana V. Drachova, Jason O. Hallstrom, Joseph E. Hollingsworth, Joan Krone, Rich Pak, and Murali Sitaraman. 2015. Teaching Mathematical Reasoning Principles for Software Correctness and Its Assessment. Trans. Comput. Educ. 15, 3, Article 15, 22 pages. DOI: http://doi.acm.org/10.1145/2716316

7. Richard M. Felder. 1993. Reaching the second tier. Journal of College Science Teaching, 23, 5, 286-290.

8. Gene Fisher and Corrigan Johnson. 2016. Making Formal Methods More Relevant to Software Engineering Students via Automated Test Generation. In Proceedings of the ACM Conference on Innovation and Technology in Computer Science Education (ITiCSE '16). ACM, New York, NY, USA, 224229. DOI: http://dx.doi.org/10.1145/2899415.2899424

9. Scott Freeman, Sarah L. Eddy, Miles McDonough, et al. 2014. Active learning increases student performance in science, engineering, and mathematics. Proceedings of the National Academy of Sciences, 111(23), 8410-8415.

10. Timothy S. Gegg-Harrison, Gary R. Bunce, Rebecca D. Ganetzky, Christina M. Olson, and Joshua D. Wilson. 2003. Studying program correctness by constructing contracts. In Proceedings of the 8th annual conference on Innovation and technology in computer science education (ITiCSE '03), David Finkel (Ed.). ACM, New York, NY, USA, 129-133. DOI: http://dx.doi.org/10.1145/961511.961548

11. Tyson R. Henry and Janine LaFrance. 2006. Integrating role-play into software engineering courses. Journal of Computing Sciences in Colleges, 22(2), 3238

12. Wayne Heym, et al.. 2017. Integrating Components, Contracts, and Reasoning in CS Curricula with RESOLVE: Experiences at Multiple Institutions. Proc. 30th Conference on Software Engineering Education and Training, IEEE, 2017.

13. Jason O. Hallstrom, Cathy Hochrine, Jacob Sorber, and Murali Sitaraman 2014. An ACM 2013 exemplar course integrating fundamentals, languages, and software engineering. In Proceedings of the 45th ACM technical symposium on Computer science education (SIGCSE '14). ACM, New York, NY, USA, 211-216. DOI: http://dx.doi.org/10.1145/2538862.2538969
14. Nabil M. Kabbani, Daniel W. Welch, Caleb Priester, Stephen Schaub, Blair Durkee, Yu-Shan. Sun, and Murali Sitaraman, 2015. Formal Reasoning Using an Iterative Approach with an Integrated Web IDE," In Proceedings $2^{\text {nd }}$ International Workshop on Formal Integrated Development Environment, EPTCS 187, June 2015, 56-71.

15. Victor Klebanov, et al., 2011. The 1st Verified Software Competition Experience Report. In FM 2011: Formal Methods, Proceedings 17th International Symposium on Formal Methods, Springer LNCS 6664, 154-168.

16. Bertrand Meyer. 1992. Applying Design by Contract. Computer, 25(10):4051.

17. Mercedes Lorenzo, Catherine Hirshfeld Crouch and Eric Mazur. 2006. Reducing the gender gap in the physics classroom. American Journal of Physics, 74, 2, 118-122.

18. Steve Olson and Donna Gerardi Riordan. 2012. Engage to Excel: Producing One Million Additional College Graduates with Degrees in Science, Technology, Engineering, and Mathematics. Report to the President. Executive Office of the President.

19. R. F. Paige and J. S. Ostroff, 2004. Specification-Driven Design with Eiffel and Agents for Teaching Lightweight Formal Methods. In: Dean C.N., Boute R.T. (eds) Teaching Formal Methods. TFM 2004. Lecture Notes in Computer Science, vol 3294. Springer, Berlin, Heidelberg.

20. Erik Poll. 2009. Teaching Program Specification and Verification Using JML and ESC/Java2. In Proceedings of the 2nd International Conference on Teaching Formal Methods (TFM '09), Jeremy Gibbons and José Nuno Oliveira (Eds.). Springer-Verlag, Berlin, Heidelberg, 92-104. DOI: http://dx.doi.org/10.1007/978-3-642-04912-5_7

21. David Preston. 2005. Pair programming as a model of collaborative learning: review of the research. Journal of Computing Sciences in Colleges, 20(4), 3945

22. Caleb Priester, Yu-Shan Sun, and Murali Sitaraman. 2016. Tool-Assisted Loop Invariant Development and Analysis. Proc. 29th Conference on Software Engineering Education and Training, IEEE, 2016.

23. Michael Prince. 2004. Does active learning work? A review of the research. Journal of Engineering Education 93.3, 223-231.

24. Elaine Seymour. 2000. Talking about leaving: Why undergraduates leave the sciences. Westview Press.

25. Susan R. Singer, Natalie R. Nielsen, and Heidi A Schweingruber. 2012 Discipline-based education research. Washington, DC: The National Academies.

26. Murali Sitaraman and Bruce W. Weide. 1994. Special Feature on RESOLVE, ACM SIGSOFT Software Engineering Notes, October 1994, 21-68.

27. Murali Sitaraman, et al., 2011. Building a Push-Button RESOLVE Verifier: Progress and Challenges," Formal Aspects of Computing 23, 607-626.

28. Paolo A.G. Sivilotti and Matthew Lang. 2010. "Interfaces first (and foremost) with Java". In Proceedings of the 41st ACM technical symposium on Computer science education (SIGCSE '10). ACM, New York, NY, USA, 515519. DOI: http://dx.doi.org/10.1145/1734263.1734436

29. Robert E. Slavin. 1991. Synthesis of research of cooperative learning. Educational Leadership 48.5, 71-82.

30. Suzanne R. Slusser and Rebecca J. Erickson. 2006. Group quizzes: an extension of the collaborative learning process. Teaching Sociology 34.3, 249262 .

31. James C. Spohrer and Eliot Soloway. 1986. Novice mistakes: Are the folk wisdoms correct?. Communications of the ACM 29, 1, 624-632.

32. Sheila Tobias. 1990. They're Not Dumb. They're Different.: A New "Tier of Talent" for Science, Change: The Magazine of Higher Learning, 22:4, 11-30.

33. Laurie Williams and Robert Kessler. 2002. Pair programming illuminated. Addison-Wesley Longman Publishing Co., Inc. 